\title{
Annuity Planning and Consumption-Investment Choices in Retirement Planning
}

\author{
Zhisheng Li and Aparna Gupta \\ Decision Sciences and Engineering Systems, Rensselaer Polytechnic Institute, Troy, NY, 12180 USA \\ Email: liz4@rpi.edu, guptaa@rpi.edu
}

\begin{abstract}
Annuities can be effective tools in managing longevity risk in retirement planning. This paper develops a framework that merges annuity purchase decisions with consumption-investment selections. After introducing a pricing model and a benefit payment model for an annuity, we construct a multi-period wealth evolution model. An optimization problem is formulated with an objective of maximizing life time utility of consumptions and wealth. Optimal decisions are determined as a trade off between consumption and investment among an annuity, a risky and a risk-free asset.
\end{abstract}

Keywords:Annuity; Annuitization; Consumptioninvestment selections; Utility; Optimization

\section{Introduction}

Due to the expanding life expectancy and the increasing significance of an individual's responsibility in retirement planning, consumption and investment decisions in retirement planning have become more challenging. In practice, different actuarial products in the market are available for hedging different risks. Individuals can hedge the risk of living too short by utilizing a conventional life insurance, as well as the risk of living too long by purchasing an annuity.

Decision problems related with annuity purchase include: selecting the optimal time to buy an annuity, choosing an appropriate type of annuity or the optimal allocation among different annuities, optimizing the premium payments structure, deciding the time of annuitization, selecting the optimal benefit period. There are several attempts in recent literature that create normative frameworks to address the above questions. These include the work in $[1,2,3]$. However, this work is either restricted due to strong assumptions (e.g., one-period model, no bequest motive, actuarially fair pricing mechanism), or incomplete consideration on other related decision variables (e.g., consumption, availability of other asset classes, and an individual's preference).

\section{Problem Formulation}

This section formulates an integrated optimization framework that merges annuity purchase decisions into consumption-investment selections in retirement planning, where the optimal decisions are determined by a trade off between immediate consumption and savings for long-term needs, and an appropriate allocation of retirement savings in an annuity, a risky asset and a risk-free asset.

\subsection{Price an Annuity}

Before introducing our mathematical models, some basic annuity terms are defined.

Accumulation Period: the time between annuity purchase and start of benefit payments.

Annuitization Time $T_{S}$ : the time converting the accumulated value of an annuity account into a series of periodic benefit payments.

Distribution Period: the period of time to receive benefits from an annuity, either a specified number of years or the purchaser's lifetime.

$R_{f}$ : return of a risk-free asset in one period;

$R_{t}^{a}$ : return of the portfolio supporting an annuity fund;

$M$ : total insurance charge in one period of an annuity;

$T_{A}$ : start of the accumulation period;

$T_{E}$ : end of the distribution period of an annuity;

$p_{x}^{i}$ : conditional survival probability that a person aged $x$ will survive additional $i$ years;

$a_{x}^{T_{S}, T_{E}}$ : price of a unit annuity for a person aged $x$ at $T_{S}$, whose benefit period is from $T_{S}$ to $T_{E}$;

$P_{t}$ : premium of an annuity in period $t$;

$V_{t}$ : benefit of a unit variable annuity in period $t$. 
$B_{t}$ : benefit payment of a variable annuity.

The premiums and benefits structure of a deferred variable annuity is shown in Figure 1, where $T_{A}$ is the time when the annuity is purchased, $T_{S}$ is the annuitization time, and $T_{E}$ is the time when the last benefit payment is issued.

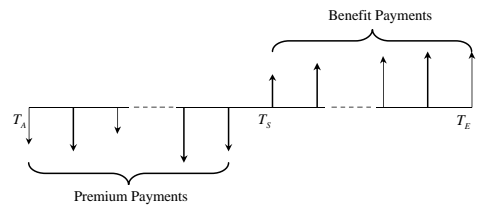

Figure 1: Premiums and benefits structure

\subsubsection{Annuity Price and Benefit Payments}

In a fixed unit annuity, the issuer guarantees the purchaser $\$ 1$ in each year of the distribution period. If the purchaser lives $i$ additional years after annuitization, the present value at of all the future benefits will be $\sum_{j=1}^{i} \frac{1}{R_{f}^{j}}$ if $1 \leq i \leq T_{E}-T_{S}+1$, and be $\sum_{j=1}^{T_{E}-T_{S}+1} \frac{1}{R_{f} j}$ if $i>T_{E}-T_{S}+1$. Given the conditional survival probability of the purchaser $p_{x}^{i}$, the price of the annuity can be described as:

$$
\begin{aligned}
a_{x}^{T_{S}, T_{E}}= & \sum_{1}^{T_{E}-T_{S}+1} p_{x}^{i} \sum_{1}^{i} \frac{1}{R_{f}^{j}} \\
& +\sum_{T_{E}-T_{S}+2}^{\infty} p_{x}^{i} \sum_{1}^{T_{E}-T_{S}+1} \frac{1}{R_{f}^{j}}
\end{aligned}
$$

When an individual purchases an annuity, the premiums he pays go into his choice of an underlying investment fund. His rate of return and therefore the accumulated value of his premiums depend on the performance of the underlying portfolios. The accumulated value of the premium payments at time $T_{S}$ is: $C P_{T_{S}}=$ $\sum_{t=T_{A}}^{T_{S}-1}\left[P_{t} \cdot \prod_{s=t}^{T_{S}-1}\left(R_{s}^{a}-M\right)\right]$.

In practice, a variable annuity ties its benefits to the performance of the underlying investment fund. The actual benefits of a variable unit annuity are $V_{t}=\prod_{s=T_{S}}^{t-1} \frac{R_{s}^{a}-M}{R_{f}}$. At time $T_{S}$, the issuer will convert the accumulated cash balance of his annuity account $\left(C P_{T_{S}}\right)$ into a series of benefit payments. The benefits will be $B_{t}=\frac{C P_{T_{S}}}{a_{x}^{T_{S}, T_{E}}} \cdot V_{t}$.

To estimate the conditional survival probability $p_{x}^{i}$, we define the survival function $S(x)$ as the probability that an individual survives to at least a specified time, that is, $S(x)=\operatorname{Pr}(X \geq x)=\frac{\sum_{i=x}^{\infty} N_{i}}{\sum_{i=0}^{\infty} N_{i}}$, where $N_{i}$ is the number of persons at age $i$ in a population. In the discrete case, the hazard function $\mu(x)$, which gives the probability that an individual will experience an event of death within a small time interval given that he has survived up to the beginning of the interval, is approximated as $\mu(x)=\frac{\ln S(x)-\ln S(x+\Delta x)}{\Delta x}$. For example, when $\Delta x=1, \mu(x)=\ln S(x)-\ln S(x+1)$. With all $\mu(x)$ given, $p_{x}^{0}=\mu(x)$. To compute $p_{x}^{i}$ for $i \geq 1$, the following procedure can be used:

$$
\begin{aligned}
p_{x}^{i} & =\mu(x+i) \cdot \sum_{t=0}^{i-1}(1-\mu(x+t)) \\
& =p_{x}^{i-1} \cdot \frac{(1-\mu(x+i-1)) \cdot \mu(x+i)}{\mu(x+i-1)}
\end{aligned}
$$

\subsubsection{Results}

To illustrate the practical implications, we compute the price of an annuity by using some real data. The data comes from the United States Life Tables for 2002, which can be obtained online through National Center for Health Statistics. Since the conditional survival probabilities for male and female are different, the price of an annuity is different for male and female. Table 1 presents the price of a lifetime fixed unit annuity for male and female based on two different risk free rates.

Table 1: Price of a lifetime fixed unit annuity

\begin{tabular}{lcclcc}
\hline & \multicolumn{2}{c}{ Male } & & \multicolumn{2}{c}{ Female } \\
\cline { 2 - 3 } \cline { 5 - 6 } Age & $3 \%$ & $5 \%$ & & $3 \%$ & $5 \%$ \\
\hline 65 & 11.7662 & 9.9384 & & 13.4848 & 11.1860 \\
70 & 9.7150 & 8.4084 & & 11.3410 & 9.6538 \\
75 & 7.7305 & 6.8507 & & 9.1734 & 8.0114 \\
80 & 5.8855 & 5.3327 & & 7.0602 & 6.3198 \\
85 & 4.2496 & 3.9278 & & 5.1404 & 4.7071 \\
\hline
\end{tabular}

\subsection{Income Model}

Labor income is the most important source of wealth and a big determinant of consumption. Stochastic labor income can influence people's saving behavior, consumption and portfolio choices significantly. In this study, however, for capturing only the first order effect of the nature of income stream, we adapt the income models developed by Viceira [4]. We remove the transitory part of the income in the model and revised the model as, $I_{t}=I_{t-1} e^{G_{t}}$, where $G_{t}=a t+b$, and $I_{t}$ denotes the income in 
period $t, G_{t}$ is an age-specified drift. According to Gupta and $\mathrm{Li}$ [5], we take the slope of the drift function, $a=-0.0013$, and the intercept, $b=0.033$.

\subsection{Wealth Evolution Model}

In this section, an individual is assumed to invest his total wealth in consumption, an annuity, a risky asset and a risk-free asset. We use $S_{t}$ to denote the return of the risky asset. At each point of time the risky asset return goes up with a probability $p=0.5$ and down with probability $1-p=0.5$, whereas the return of the risk-free asset $R_{f}$ remains constant. We denote the return of the risky asset on the "up" by $S_{u}$ and $S_{d}$ on the "down." Let the wealth level in period $t$ is $W_{t}$. If $X_{t}$, and $1-X_{t}$ are employed to denote the proportion of the total wealth invested in the risky asset and risk-free asset in period $t$, the wealth one would have in the next period will be $W_{t}\left[X_{t} S_{u}+\left(1-X_{t}\right) R_{f}\right]$ if an "up" occurs and $W_{t}\left[X_{t} S_{d}+\left(1-X_{t}\right) R_{f}\right]$ if a "down" occurs. Including periodic incomes, consumptions and annuity premiums and benefits, we have the following wealth evolution model:

$W_{t+1}=\left[W_{t}+I_{t}-C_{t}-P_{t}+B_{t}\right]\left[X_{t}\left(S_{t}-R_{f}\right)+R_{f}\right]$, $S_{t}=\left\{\begin{array}{ll}S_{u}, & \text { with prob. } p \\ S_{d}, & \text { with prob. } 1-p\end{array}\right.$,

$1 \geq X_{t} \geq 0, W_{t} \geq 0, C_{t} \geq C_{t}^{*}, t=0,1, \cdots, T$

where $C_{t}^{*}$ is the minimum consumption level to support the basic standard of living in period $t$.

\subsection{Optimization Problem}

To guarantee the long-term well being after retirement, an individual is required to make a trade off between immediate consumption and savings for long-term consumption needs. To keep the asset growth and to hedge the potential longevity risk, the individual also needs to decide on whether and when to purchase an annuity and the appropriate allocation of the total asset in different asset classes based on his wealth status. The objective function for this optimization problem can be formulated as:

Obj : $\max _{X_{t}, P_{t}, C_{t}, T_{S}, T_{E}} \sum_{t=0}^{T} \eta_{t} E\left[U\left(C_{t}\right)\right]+\eta_{T} E\left[U\left(W_{T}\right)\right]$

where $T$ is the planning horizon, $\eta_{t}$ is the time discount ratio. The time discount ratio can be further modeled as $\eta_{t}=\delta^{-t}$, and $\delta$ is the time-preference parameter.

\section{Computational Results}

If the utility function is assumed to be of the form yielding constant relative risk aversion, then we can let $U(C)=\frac{C^{\gamma}-1}{\gamma}$, where $\gamma<1$ and $\gamma \neq 0$. $\frac{-U^{\prime \prime}(C(t)) C(t)}{U^{\prime}(C(t))}=1-\gamma$ is the Pratt's measure of relative risk aversion. In finance theory, high risk averters denote those with $1-\gamma>1$ (i.e., $\gamma<0$ ), and low risk averters (or risk seeker) are those with $1-\gamma<1$ (i.e., $\gamma>0$ ).

We solve a 26 years problem for an individual at 54 years of age. The following parameter values are applied: $R_{f}=1.05, S_{u}=1.25, S_{d}=0.9$, $R^{a}=1.06, M=0.02, W_{0}=15, C_{1}=3, \delta=1.027$, $\gamma=0.5$ for risk seeker and $\gamma=-0.5$ for high risk averters. We first solve the problem by forcing the proportion in risky asset investment $X_{t}$ to 0 . In Figure 2(a), the optimal age of annuitization is between 58 and 59 years, and the annuity becomes unprofitable after 64 . The existence of risky asset delays the annuitization. The optimal age of annuitization increases to between age 60 and 61 when $X_{t}$ is free in $[0,1]$. The age when the annuity becomes unprofitable is still 64 . Moreover, the scale of the utility also increases when the risky asset is introduced, Figure2(b).
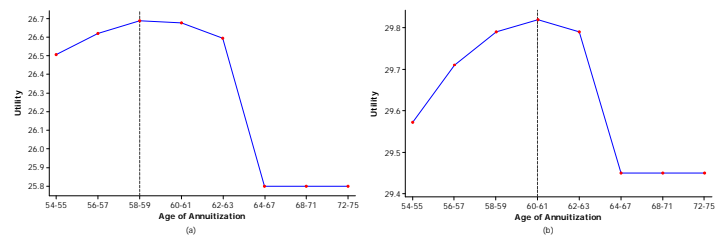

Figure 2: (a) $X_{t}=0$, (b) $X_{t} \in[0,1]$

Figure 3 presents the allocation of total wealth at the optimal annuitization time for 4 scenarios: (1) optimal annuitization for a risk seeker; (2) Selfannuitization for a risk seeker; (3) Optimal annuitization for a high risk averter; (4) Self-annuitization for a high risk averter.

For a risk seeker, we see no wealth allocated in the risk-free asset for all the 8 nodes under the optimal strategy. At low wealth levels, the individual selects to annuitize some or all of his available wealth. As the wealth level increases, the amount invested in the annuity decreases, while the amounts in consumption and the risky asset increase. There is no wealth annuitized once a certain high wealth level is achieved(nodes 6-8). When the annuity is not included in the investment, the risk-free asset takes the place. The wealth allocations for a high risk averter are comparable with 


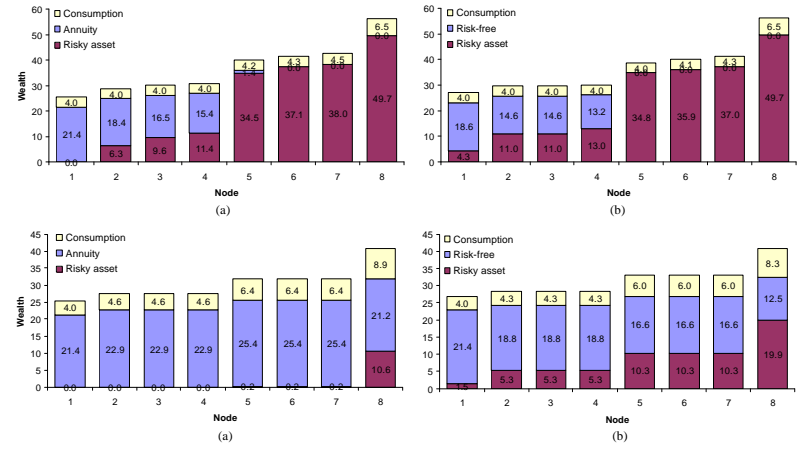

Figure 3: (a) Risk seeker, with annuity, (b) Risk seeker, without annuity, (c) High risk averter, with annuity, (d) High risk averter, without annuity

those for a risk seeker. However, a risk averter allocates significantly more wealth in the annuity under the optimal annuitization strategy, and more in the risk-free asset under the self-annuitization strategy. These phenomena are consistent with the conventional investment wisdom. It is commonly expected that as the funding level falls investors might shift into low-risk assets to protect their position.
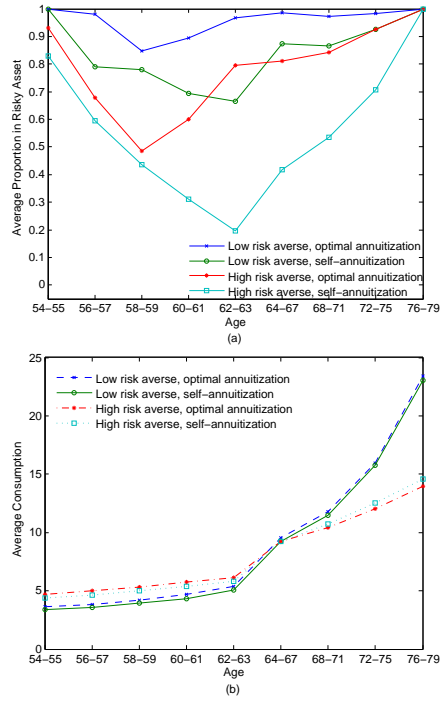

Figure 4: (a) Investment, (b) Consumption.

We plot the average proportions allocated in the risky asset and the average period consumptions for the 9 periods in Figure 4. Five points are worth noting: (1) The proportion in the risky asset decreases from 1 in the first period to some point and then increase back to 1 in the last period for all the scenarios; (2) The existence of annuity makes individuals more aggressive and invest more in the risky asset; (3) Risk seekers tend to allocate more in the risky asset than high risk averters; (4) High risk averters prefer to have more stable consumption level than Risk seekers; (5) Individuals with different degree of risk aversion make use of the annuity in different ways. Higher risk averters use the annuity to achieve as high as possible consumption for each period, while risk seekers utilize it to achieve more stable consumptions.

\section{Conclusions}

Motivated by the recent interest on the topic of annuity planning, this paper constructed a integrated framework which merged annuity decisions into optimal consumption-investment selections. Computational results are presented to demonstrate the practical implications of the framework for different scenarios based on the availability of an annuity and the risk aversion degree of the investor.

\section{References}

[1] S. Kapur and M. Orszag, "A portfolio approach to investment and annuitization during retirement," working paper, Birkbeck College, University of London, 1999.

[2] P. Chen and M. A. Milevsky, "Merging asset allocation and longevity insurance: An optimal perspective on payout annuities," Journal of Financial Planning, vol. 16, no. 6, pp. 52-62, 2003.

[3] M. A. Milevsky and V. R. Young, "The timing of annuitization: Investment dominance and mortality risk," The Individual Finance and Insurance Decisions Center: http://www.ifid.ca/research.htm, 2005.

[4] L. M. Viceira, "Optimal portfolio choice for long-horizon investors with nontradable labor income," Journal of Finance, vol. 56, no. 2, pp. 433-470, 2001.

[5] A. Gupta and L. Li, "Behavioral modeling in optimal investment-consumption decisions for long-term financial planning," The Proceedings of the Third International Conference on Computational Intelligence in Economics and $\mathrm{Fi}$ nance, North Carolina, 2003. 